\title{
QUALITY ASSURANCE SYSTEMS IN EDUCATION AND TRAINING IN EUROPE
}

\author{
CLAUDIU SORIN VOINIA \\ Ph.D student, Faculty of Engineering /Department of Industrial Engineering, „Lucian Blaga” University of \\ Sibiu,Romania,voiniac@yahoo.com \\ ANA TUSA \\ Ph.D.student,Faculty of Economics /Department of Management, „Lucian Blaga” University of Sibiu, Romania, \\ anatusa71@yahoo.com \\ CARMEN SIMION \\ Univ.Ph.D professor, Faculty of Engineering /Department of Industrial Engineering, „Lucian Blaga” University \\ of Sibiu, Romania,carmen.simion@ulbsibiu.ro
}

\begin{abstract}
Member States have a duty to compare and learn more about the national education and professional training. The objectives of this paper were to identify specific characteristics, developments and highlighting key priorities in coordinating the development of specific quality assurance processes in the European Union.

The aim of this work was to present the quality assurance systems in vocational education and training systems in the Member States of the European Union.

The results were to identify the extent to which national initiatives of EU member States show interest in the quality of education.

Data from research can be useful in developing strategic sector development programs, and local schools.
\end{abstract}

Keywords: Quality assurance, trening, education.

\section{Introduction}

There isn't and there cannot be a unique concept of quality but standardized procedures and general principles that apply to quality management systems. Design of systems and procedures for quality assurance is the result of social choices that are based on a culture and a clear strategic vision to establish the optimal development of the school system.

This requires a national strategy that is based on values and principles that are explicit and operationalized in systems, indicators, standards and procedures to all levels of the national education system, regional / county local educational institution.(1)

\section{Summary of quality assurance systems in the Member States}

\section{Austria (AT)}

Federal Ministry of Education, Arts and Culture (BMUKK) in charge of responsibilities and structure of schools in Austria has the responsibility of ensuring the quality of education and training. BMUKK established National Reference Point for Quality Assurance in Education and Training with the central task of promoting the culture of quality in IPT schools in Austria and linkages between stakeholders.(IES, 2005)

\section{Bulgaria (BG)}

Vocational Education and Training Law (1999) established a special body, the National Agency for Education and Training (NAVET). NAVET main objective is "to ensure and maintain quality education 
and training for youth and adults, according to labor market needs and develop the competitiveness of the Bulgarian economy."

\section{Cyprus (CY)}

From FPI and FPC reports results that the current practice of quality assurance inspection in Cyprus is used as a method of monitoring quality. These inspections are conducted every two years in technical schools, apprenticeship system also uses inspectors and process monitoring HRDA also includes inspection, in addition to quality assessment step program approval and payment of subsidies.

\section{Czech Republic (CZ)}

Quality Assurance in EFP in the Czech Republic is defined in the Long-Term Plan for the Development of Education and substandard teaching in 2002, and its updated version for 2004 to 2008. This plan provides that one of the main priorities to be, quality assurance, monitoring and evaluation of education. Czech state guarantees the quality of the educational offer in terms of courses accredited by the Ministry of Education, Youth and Sports (MSMT) and external assessment - inspection by the Czech School Inspectorate (CSI).

\section{Denmark (DK)}

The Ministry of Education is responsible for the inspection and quality assurance. Common Quality Assurance Framework (CQAF) is part of the national policy, but with freedom providers regarding the implementation. Although the Ministry has overall responsibility, other actors play important roles: social partners, especially trade committees and local committees training, but also the trainees and businesses through business associations.

\section{Estonia (EE)}

Quality Assurance as a principle and a number of tools for quality assurance in EFP were developed in Estonia since the mid1990s. In 2003, model and Quality Award competition, based on the European Foundation for Quality Management (EFQM) was developed for IPT schools in Estonia.

\section{Finland (FI)}

The Ministry of Education is responsible for the strategic direction and standards of EFP and leads the national development. National objectives of EFP qualifications framework and core subjects included in these are set by the government. Details of qualification and training level are determined by the Ministry of Education. EFP supply license is granted by the Ministry.

\section{France (FR)}

Ministry of Education in France is the body responsible for defining strategies, policies, framework and teaching and learning programs and provides staff recruitment and management training activities. The Ministry is also responsible for vocational education at secondary level, including a national curriculum, examinations and diplomas, recruitment, training and other related activities. Moreover, the Department as "Higher Council for Evaluation" evaluates the performances and activities of teacher training covering the secondary domain of professional training.

\section{Germany (DE)}

In Germany Quality assurance has traditionally been acquired through supervision and monitoring of education and training by the state. BMBF has commissioned BIBB to establish a National Reference Point for Quality Assurance in Education and Training (DEQA-VET). DEQAVET activity aimed not only persons holding positions of responsibility in education and training, but also organizations, companies and businesses, ensuring quality in their education and training or working on it.

\section{Greece (EL)}

In recent years many of the changes promoted in Greece are directly related to EU work program "Education and Training 2010".

\section{Hungary (HU)}

In Hungary, the government resolution on the implementation of the 2005 strategy focused on developing EFP introduction of a monitoring system career training for adults until December 2008. 


\section{Ireland (IE)}

According to the mission statement, the mission of the Irish Department of Education and Science (DES) is "to provide high quality education that will enable people to achieve their full potential and to participate fully as members of society, and contribute to social development, cultural and economic development of Ireland ". To pursue this mission, the Department has established five high level objectives. One of them is "to promote quality outcomes." This suggests that DES is the main body of quality assurance in the Irish education system.

Italy (IT)

Quality assurance systems implemented by Italy in education and training, primarily revolve around the quality of supply. However, by 2006 , developments in quality mainly targeted quality control rather than quality improvement. Therefore, practitioners felt that attention to quality is a constraint rather than an opportunity.

\section{Latvia (LV)}

Since 2005 in Latvia was established quality evaluation system of school education for general education in the purview of the Education Development Concept for 2002-2005. Since 2009, State Service Quality in Education is responsible for accreditation of providers of professional education organization in accordance with the Rules of Procedure of the Cabinet of accrediting training programs, educational institutions and examination centers and certification of headmasters of professional education (2005, 2007).

\section{Lithuania (LT)}

Responsibilities in quality assurance defined by the Laws of Education and Training, which are implemented based on quality assessment and monitoring internal and external providers. The main responsibility for quality assurance EFP belongs to EFP provider such as:

- with stakeholders responsible to quality training;

- organize training programs that meet the needs of the economy and the standard relevant;

- implementing internal evaluation and supply management training.

\section{Luxembourg (LU)}

In Luxembourg for the last 10 years there has been an extensive review of the entire system of education and training. Establish administrative structures necessary for modern school management started a review of the mission system and those working in the field provided a degree of autonomy.

\section{Malta (MT)}

Several policy initiatives and structures have been defined to improve quality management at the institutional level. The role of teachers and the need to improve their teaching skills and ability focus on the National Minimum Curriculum.

\section{Netherlands (NL)}

Quality assurance is a key priority in education policy. The institutions have a great deal of autonomy to design their own systems of quality assurance. Self-evaluation by institutions is the starting point for external quality assurance under the responsibility of the Inspectorate for Education.

\section{Poland (PL)}

The system controlled by the Minister of Education, including adult schools, further education institutions, practical training centers and training centers, educational supervision is carried out by school principals and school administrators.

\section{Portugal (PT)}

Quality assurance in EFP is a cross-cutting issue that is more relevant today, not only to make major changes (such as ensuring the effectiveness of EFP systems, facilitating access to EFP and strengthen the relationship between EFP and labor), but also to extend the monitoring of results (by reference to objectives).

\section{Romania (RO)}


In Romania a law on quality assurance in education was elaborated with provisions relating to performance standards, norms, and indicators related to the quality of the national education system, quality of service suppliers, and the quality of education and training. Among the major entities involved in quality assurance (QA) EFP system are:

- Ministry of Education, which has overall responsibility for education and training within the formal education system and develop strategies and policies, preparing legislation and administers public education.

- The Ministry of Labour, Family and Equal Opportunities ( MMFES ) and its regional branches, directorates County Labour and Social Welfare is responsible for retraining and training of the workforce.

- National Centre for the Development of Vocational and Technical Education ( CNDIPT ) plays a major role in ensuring the quality and developed the National Quality Assurance

(CNAC) for TVET in Romania, based on the Common Quality Assurance Framework (CQAF ), and the two main instruments of quality assurance at provider level: Self- Assessment Manual, based on European Guidelines for Self- Assessment Manual Inspection VET providers and external providers to monitor VET ( TVET ).

- Institutions involved directly in QA with an important role are: Romanian Agency for Quality Assurance in Pre (ARACIP) and the Romanian Agency for Quality Assurance in Higher Education (ARACIS).

By the entry into enforcement of Law of National Education in early 2011 it was created the opportunity to develop a national framework for quality assurance in education was elaborated and training.

\section{Conclusions}

From the research carried out on the quality assurance in education and training in several EU Member States and Romania was observed that the implementation of the recommendation of the European Parliament and of the Council establishing the European reference framework for quality assurance in education and training is underway for most European countries existing different approaches on each indicator.

Quality

assurance in education and training in Romania complies with the requirements of European and even we situate ourselves at the forefront of European approaches. Quality assurance implemented in Romania meet the 4 steps: planning, implementation, evaluation and revision while defining a methodology for quality assurance in which an important role is self-evaluation.

\section{References}

- Birzea C., (coordinator), The national education indicators Publishing Institute of Education Sciences, Bucharest, 2005.

- Institute of Education Sciences,( 2005), Ensuring quality - Guidelines for schools.

- Law no. 27/2006 for the approval O.U.G. No. 75/2005 on quality assurance in education.

- http://aracip.edu.ro

- http://www.tvet.ro

- http://europa.eu.int 